\title{
The Analysis of Correlation between Depression Symptoms and Their Attitudes towards Addictive Substances of High School Students Who Participate in Regular Exercise and Students Who Do Not Participate in Regular Exercise
}

\author{
Nurgul Tezcan Kardas (Corresponding author) \\ Sport Sciences Faculty of Sports Administration \\ Duzce University, Turkey \\ E-mail: nur_tezcan@hotmail.com
}

Received: September 3, 2018 Accepted: October 25, 2018 Published: October 28, 2018

doi:10.5296/jei.v4i2.13735 URL: https://doi.org/10.5296/jei.v4i2.13735

\begin{abstract}
In this study, it is aimed to analyze the correlation between depression levels and the attitudes towards addictive substances of the students participating and not participating in sports who live in Hendek district of Sakarya province and to determine if sports have an effect on depression and attitudes towards addictive substances. Also by using Vocational and Technical High schools and Anatolian High schools, it became possible to see the effect of school type. Furthermore, the effect of sociodemographic variables such as sex, grades, marital status of parents, and branch of sports, duration and frequency of participation in sports, income level, and number of siblings was researched. The study group consists of 326 students and "Demographic Information Form" developed by the researcher, "Beck Depression Inventory" and "Attitude towards Addictive Substances Scale" were used as data collection tools. The obtained data was statistically analyzed by using SPSS 25.00 program. While no difference was observed in depression symptoms for the individuals participating and not participating in sports in the general frame, it is determined that the individuals participating in sports has a higher interest in addictive substances when compared to their peers who do not participate in sports. Moreover, this negative attitude towards addictive substances is higher in male students and in the students who study at Vocational and Technical High schools.
\end{abstract}


Keywords: Depression, Addictive, Exercise, Student, High school

\section{Introduction}

Adolescence period is an in-between period which starts with the step into puberty and youth and continues with the discovery of identity, and ends with identity achievement. When considered in general sense, there occur various physical, social and psychological changes and developments in this period which takes part in 12-22 years of age (Alisinanoğlu, 2002). In this period, the changes occurring in individuals cause differences in their hormone system. This differentiation causes sudden changes in their emotional periods. Sometimes they might become very happy and sometimes they might become very furious. However, the rate of depression incidence in the individuals who has difficulty in understanding the cause of these changes is high (Gül \& Güneş, 2009). On account of these reasons, an adolescent individual can experience toing and froing by going into his/her shell. He/she spends most of the time with what they fictionalize. The adolescent individual, who is in search of identity, becomes more interested in his/her friends in this breaking point and this might result in obtaining a negative identity. One of the first results of negative identity will be addictive substance usage (Türker, 2016). One of the most common illnesses to be come across in the society is flu and it is possible to define depression as the flu of the soul. In that sense, depression is a problem which can always confront us just like flu (Cengil, 2003). The most common symptoms in depression are collapse, lack of energy, being unable to be happy, disturbed sleep, diminishing appetite or increase in appetite and diminishing in libido (Karamustafalıoğlu \& Yumrukçal, 2011). There are deprivation emotions such as lack of ability, becoming ugly, unsuccessfulness, and loss of girlfriend/boyfriend in the basis of depression. Psychosocial activities which will distract the adolescent individual from these problems and deprivations are required. Otherwise, this period which is already complicated will become more and more complicated (Güney, 1998).

Depressive symptoms, crisis, curiosity, and search for entertainment occurring in this complicated period show themselves as the reasons of addictive substance use (Babuna, 2009). Addictive substances are the substances which are unstoppably desirable, which arouse a feeling of increasing dose each time, and which arouse a feeling of constant use both physically and psychologically (İçli, 1999). Addictive substances are considered in 13 groups in DSM-IV. These are alcohol, nicotine, caffeine, opiates, cannabis, cocaine, inhalants, hallucinogens, amphetamines and sympathicomimetics, sedatives, hypnotics and anxiolytics, arylcyclohexamines, phencyclidines, multiple substances and others. On the other hand, the usage occurring during adolescence can both happen as a result of very complicated reasons and result in the occurrence of other psychological and sociological problems (Türker, 2016).

It is required to include activities supporting social and emotional development in the adaptable acquisition of identity for the individuals starting their adolescent period. At this point, sports display its significance (Öztürk \& Şahin, 2007). The sociality of the environment draws the attention in terms of sports participation's providing with some psychological benefits for adolescent individuals. As a consequence, its contributions to psychology give a good account of itself. Sports contribute to the development and 
realization for people in terms of many aspects (Salar et.al, 2012). It can generally be said that the positive effects of sports is more than the ones which can be mentioned. As a result, while participation in sports is very crucial in every phase of life, it becomes more important in the adolescence period which includes identity achievement and which can also bring about depression along with substance addiction because it displays itself in the key areas such as continuation of health, psychosocial wellbeing and self-concept (Alpaslan, 2012).

\section{Tool and Method}

In this section, there are research model, the study group which consists of people participating in the study voluntarily for obtaining data, the tools used during the obtainment of related data, and explanations related to the statistical techniques used in the analysis of the data.

\subsection{Research Model}

In this research, relational method and causal-comparative method of quantitative research methods were used.

With this research, if the attitudes of high school students, participating and not participating in regular exercise, towards addictive substances and their depression symptoms significantly differ was analyzed; and also these students' attitudes towards depression and addictive substances were analyzed in terms of some sociodemographic variables.

\subsection{Study Group}

The study group of the research consists of 326 individuals studying at Vocational and Technical High schools and Anatolian High schools running under the Ministry of National Education in Hendek District of Sakarya Province in Turkey. The criteria for the individuals included in the research were that they are between 14 and 18 years of age, that they are students of Vocational or Anatolian High schools and that they do not receive an advanced level mental, neurological or psychiatric diagnosis.

\begin{tabular}{|l|l|l|l|}
\hline Variable & & F & \% \\
\hline \multirow{4}{*}{ Sex } & Female & 170 & 52.1 \\
\cline { 2 - 4 } & Male & 156 & 47.9 \\
\hline \multirow{4}{*}{ Gchool Type } & Vocational and Technical & 176 & 54.0 \\
\cline { 2 - 4 } & Anatolian & 150 & 46.0 \\
\hline \multirow{5}{*}{ Grades } & $9^{\text {th }}$ Grade & 138 & 42.3 \\
\cline { 2 - 4 } & $10^{\text {th }}$ Grade & 61 & 18.7 \\
\cline { 2 - 4 } & $11^{\text {th }}$ Grade & 88 & 27.0 \\
\cline { 2 - 4 } & $12^{\text {th }}$ Grade & 39 & 12.0 \\
\hline
\end{tabular}




\begin{tabular}{|c|c|c|c|}
\hline \multirow{2}{*}{ Parents' Marital Status } & Together & 311 & 95.4 \\
\hline & Divorced & 15 & 4.6 \\
\hline \multirow{3}{*}{ Economic Situation } & $0-2000 \mathrm{TL}$ & 167 & 51.2 \\
\hline & $2001 \mathrm{TL}$ and over & 159 & 48.8 \\
\hline & Only Child & 18 & 5.5 \\
\hline \multirow{4}{*}{ Number of Siblings } & I have 1 sibling & 69 & 21.2 \\
\hline & I have 2 siblings & 90 & 27.6 \\
\hline & I have 3 siblings & 86 & 26.4 \\
\hline & I have more than 3 siblings & 63 & 19.3 \\
\hline \multirow{2}{*}{ Sports Participation } & Yes. he/she does & 119 & 36.5 \\
\hline & No. he/she doesn't & 207 & 63.5 \\
\hline \multirow{4}{*}{ Sports Participation Duration } & He/She doesn't & 207 & 63.5 \\
\hline & For one year & 46 & 14.1 \\
\hline & For $2-4$ years & 39 & 12.0 \\
\hline & For five years or more & 34 & 10.4 \\
\hline \multirow{5}{*}{ Sports Participation Frequency } & He/She doesn't & 207 & 63.5 \\
\hline & Every day & 27 & 8.3 \\
\hline & 3-4 days a week & 44 & 13.5 \\
\hline & 1-2 days a week & 43 & 13.2 \\
\hline & Less than a day in a week & 5 & 1.5 \\
\hline
\end{tabular}

\subsection{Data Collection Tools}

The inventories applied in order to collect data are "Demographic Information Form" prepared by the researcher, "Beck Depression Inventory" measuring depression symptoms and "Attitude towards Addictive Substances Scale" measuring attitudes towards addictiveness.

\subsubsection{Beck Depression Inventory}

Beck Depression Inventory is an inventory consisting of 21 questions which is developed in order to determine the degree of depression symptoms which are related to somatic, emotional, cognitive and motivational ones. In the study related to the reliability of the inventory carried out by Hisli (1988), the split-half reliability coefficient of the inventory was found 0.74 . There are 4 evaluation items in each category and scores between 0 and 3 are 


\section{Macrothink}

obtained from the items. As a result, the highest score to be obtained from the inventory is 63 . The higher the score is, the more depression symptoms are existent.

\subsubsection{Attitude Towards Addictive Substances Scale}

The scale which was developed by Aksoy (2006) is one dimensional and it involves reverse items. In the 5 point rating scale, the internal consistency coefficient of 45 items is .92 . This survey designed in order to measure attitudes towards addictive substances is in the level of providing with scores between 45 and 225 . High scores denote the negativity of the attitudes related to addictive substances and low scores denotes that there are positive attitudes.

\subsection{Analysis of Data}

SPSS 25 pack program was used in the analysis of the data. Frequency analysis was made in order to determine the sociodemographic features of the individuals forming the sample group. "T-test" and "One-way Anova" test were used in the data with normal distribution in order to test if the individuals participating in the research demonstrate difference in terms of their sociodemographic features. Their attitudes towards depression and addictive substances were also questioned with the Pearson Correlation test.

\section{Results}

In this section of the research, there are findings related to the data obtained as a result of the statistical analyses, and comments related to the findings.

In table 1, there is information about the analysis of the correlation between depression and attitudes towards addictive substances of the individuals who participated in the regular exercise and the individuals who do not participate in the regular exercise.

Table 1. Pearson correlation test results of attitude towards addictive substances scale and beck depression inventory

\begin{tabular}{|l|l|l|l|}
\hline & & $\begin{array}{l}\text { Attitude towards Addictive } \\
\text { Substances Scale }\end{array}$ & $\begin{array}{l}\text { Beck Depression } \\
\text { Inventory }\end{array}$ \\
\hline \multirow{3}{*}{$\begin{array}{l}\text { Attitude towards Addictive } \\
\text { Substances Scale }\end{array}$} & Pearson Correlation & 1 & .373 \\
\cline { 2 - 4 } & $\mathrm{P}$ & & $\mathbf{. 0 0 0 *}$ \\
\cline { 2 - 4 } & $\mathrm{N}$ & 326 & 326 \\
\hline \multirow{3}{*}{ Beck Depression Inventory } & Pearson Correlation & .373 & 1 \\
\cline { 2 - 4 } & $\mathrm{P}$ & $\mathbf{. 0 0 0}^{*}$ & 326 \\
\cline { 2 - 4 } & $\mathrm{N}$ & 326 & \\
\hline
\end{tabular}

Note. ${ }^{*} \mathrm{P}<.05$.

According to the Pearson Correlation test results which were used in order to analyze the 


\section{Macrothink}

correlation between "Attitude towards Addictive Substances Scale" and "Beck Depression Inventory", a positive correlation between "Attitude towards Addictive Substances Scale" and "Beck Depression Inventory" was found. Accordingly, it can be said that the individuals with the tendency of addictive substance use also has tendency towards depression.

Table 2. T-test results according to sports participation

\begin{tabular}{|l|l|l|l|l|l|}
\hline & Sports Participation & $\mathbf{N}$ & $\mathbf{X}$ & $\mathbf{S S}$ & $\mathbf{P}$ \\
\hline \multirow{2}{*}{$\begin{array}{l}\text { Attitude towards Addictive } \\
\text { Substances Scale }\end{array}$} & He/she does & 119 & 2.1173 & .72528 & \multirow{2}{*}{.017* } \\
\cline { 2 - 6 } & He/she doesn't & 207 & 1.9099 & .76978 & \\
\hline \multirow{2}{*}{ Beck Depression Inventory } & He/she does & 119 & 1.7995 & .68253 & \multirow{2}{*}{709} \\
\cline { 2 - 6 } & He/she doesn't & 207 & 1.7704 & .67496 & \\
\hline
\end{tabular}

Note. ${ }^{*} \mathrm{P}<.05$.

According to the results of t-test which was done in order to determine if the average scores of high school students from Beck Depression Inventory show significant differences in terms of sports participation variable, the difference between average scores are insignificant $(\mathrm{P}=709)$. On the other hand, when the scores of Attitude towards Addictive Substances are studied in terms of sports participation variable, the differences between average scores are significant according to the t-test results. According to the obtained findings, the attitude towards addictive substances scores of the students who participate in regular exercise is higher. That is, it can be said that there is a tendency for addictive substances in the students participating in the regular exercise. 
Table 3. One-way Anova test results according to the sports participation frequency variable

\begin{tabular}{|c|c|c|c|c|c|}
\hline & Sports Participation Frequency & $\mathbf{N}$ & $\mathrm{X}$ & SS & $\mathrm{P}$ \\
\hline \multirow{6}{*}{$\begin{array}{l}\text { Attitude towards Addictive } \\
\text { Substances Scale }\end{array}$} & He/She doesn't & 207 & 1.9216 & .76999 & \multirow{6}{*}{.133} \\
\hline & Every day & 27 & 2.2862 & .80805 & \\
\hline & 3-4 days a week & 44 & 2.0294 & .71241 & \\
\hline & 1-2 days a week & 43 & 2.0862 & .68268 & \\
\hline & Less than a day in a week & 5 & 1.7591 & .83946 & \\
\hline & Total & 326 & 1.9856 & .75933 & \\
\hline \multirow{6}{*}{ Beck Depression Inventory } & He/She doesn't & 207 & 1.7704 & 67746 & \multirow{6}{*}{$.000 *$} \\
\hline & Every day & 27 & 2.3228 & .83250 & \\
\hline & 3-4 days a week & 44 & 1.6061 & .56655 & \\
\hline & 1-2 days a week & 43 & 1.6224 & .45974 & \\
\hline & Less than a day in a week & 5 & 2.2000 & .77181 & \\
\hline & Total & 326 & 1.7810 & .67683 & \\
\hline
\end{tabular}

Note. $* \mathrm{P}<.05$.

One-way Anova Test was applied in order to determine if there is a difference between average scores obtained from Attitude towards Addictive Substances Scale of the students in the research group according to the sports participation frequency. Accordingly, there is not a high level and significant difference. However, when the average scores are considered, it is seen that the average scores of the individuals who participate in sports everyday is higher than other individuals.

At the same time, when the difference between average scores obtained from Beck Depression Inventory in terms of sports participation frequency is considered, a significant difference is observed. According to the obtained results, it can be said that the individuals who do exercise everyday and the individuals who do exercise less than one day in a week period have higher scores for depression symptoms than the other individuals when the data obtained from Tukey test which is applied in order to determine the rates among the groups are considered. 
Table 4. T-test results according to the sex variable

\begin{tabular}{|l|l|l|l|l|l|}
\hline & Sex & N & X & SS & P \\
\hline \multirow{2}{*}{$\begin{array}{l}\text { Attitude towards Addictive } \\
\text { Substances Scale }\end{array}$} & Female & 170 & 1.6951 & .68116 & \multirow{2}{*}{$.00 *$} \\
\cline { 2 - 6 } & Male & 156 & 2.3022 & .71390 & \\
\hline \multirow{2}{*}{ Beck Depression Inventory } & Female & 170 & 1.7896 & .61181 & \multirow{2}{*}{.811} \\
\cline { 2 - 6 } & Male & 156 & 1.7717 & .74312 & \\
\hline
\end{tabular}

Note. ${ }^{*} \mathrm{P}<.05$.

T-test analysis was made in order to examine the correlation between sex variable and attitude towards addictive substances and depression symptoms of the high school students participating and not participating in regular exercise. According to the statistical results, average score that male students got from the attitude towards addictive substances scale is significantly different from the average scores of the female students. Accordingly, the attitudes of the male students towards addictive substances are more negative when compared to the attitudes of the female students. The male students have a higher tendency towards addictive substances. When the results are considered in terms of depression, the difference between average scores are insignificant. Depression symptoms do not display differences for sex variable.

Table 5. T-test results according to school type variable

\begin{tabular}{|l|l|l|l|l|l|}
\hline & School Type & $\mathbf{N}$ & $\mathbf{X}$ & SS & P \\
\hline \multirow{2}{*}{$\begin{array}{l}\text { Attitude towards Addictive } \\
\text { Substances Scale }\end{array}$} & Vocational High school & 176 & 2.1778 & .76393 & \multirow{2}{*}{$00 *$} \\
\cline { 2 - 6 } & Anatolian High school & 150 & 1.7600 & .69090 & \\
\hline \multirow{3}{*}{ Beck Depression Inventory } & Vocational High school & 176 & 1.8252 & .73022 & \multirow{2}{*}{.202} \\
\cline { 2 - 6 } & Anatolian High school & 150 & 1.7292 & .60657 & \\
\hline
\end{tabular}

Note. $* \mathrm{P}<.05$.

The study was applied to the Vocational and Technical High school students and Anatolian High school students. T-test was applied in order to determine if the average scores of these students obtained from Beck Depression Inventory show a significant difference or not. According to the obtained results, while there is no certain differences between average scores, the average score of the students from vocational and technical high schools were found higher. When the attitudes towards addictive substances are considered, the average scores are significantly different. When approached in this sense, the average scores of vocational and technical high school students are higher than the students of Anatolian high 
school. Thus, the attitudes of vocational and technical high school students towards addictive substances are more negative than the Anatolian high school students. Therefore, it can be said that the students studying at vocational high schools tend to use addictive substances more.

Table 6. One-way Anova test results according to the class grades variable

\begin{tabular}{|c|c|c|c|c|c|}
\hline & Grades & $\mathbf{N}$ & $\mathrm{X}$ & SS & $\mathbf{P}$ \\
\hline \multirow{5}{*}{$\begin{array}{l}\text { Attitude towards Addictive } \\
\text { Substances Scale }\end{array}$} & $9^{\text {th }}$ Grade & 138 & 1.8647 & .74363 & \multirow{5}{*}{.001} \\
\hline & $10^{\text {th }}$ Grade & 61 & 2.2765 & .72794 & \\
\hline & $11^{\text {th }}$ Grade & 88 & 1.8988 & .69570 & \\
\hline & $12^{\text {th }}$ Grade & 39 & 2.1544 & .87021 & \\
\hline & Total & 326 & 1.9856 & .75933 & \\
\hline \multirow{5}{*}{ Beck Depression Inventory } & $9^{\text {th }}$ Grade & 138 & 1.7119 & .61075 & \multirow{5}{*}{.000} \\
\hline & $10^{\text {th }}$ Grade & 61 & 1.7463 & .69289 & \\
\hline & $11^{\text {th }}$ Grade & 88 & 1.7008 & .52824 & \\
\hline & $12^{\text {th }}$ Grade & 39 & 2.2613 & .95143 & \\
\hline & Total & 326 & 1.7810 & .67683 & \\
\hline
\end{tabular}

Note. ${ }^{*} \mathrm{P}<.05$.

According to the results of One-Way Anova which is applied to determine if the high school students' scores of Beck Depression Inventory show a significant difference in terms of class grades variable, the difference among average scores are significant. According to the results of Tukey test which is applied to determine among which groups this difference occurs, $12^{\text {th }}$ grade students' average scores from Beck Depression Inventory is significantly higher that $9^{\text {th }}$, $10^{\text {th }}$, and $11^{\text {th }}$ grade students' average scores. Therefore, depression symptoms can be observed in $12^{\text {th }}$ grade students more.

One-Way Anova test was applied in order to determine if the average scores obtained from Attitude towards Addictive Substances Scale show difference in terms of class grade. According to the obtained results, the difference among average scores is significant. According to the results of Tukey test which is used in order to determine among which groups this difference occurs, average scores of $10^{\text {th }}$ and $12^{\text {th }}$ grade students for attitudes towards addictive substances are significantly higher than $9^{\text {th }}$ and $11^{\text {th }}$ grade students' average scores for the same scale. In this sense, it can be stated that $10^{\text {th }}$ and $12^{\text {th }}$ grade students have a greater tendency to use addictive substances. 
Table 7. T-test results according to marital status of parents variable

\begin{tabular}{|l|l|l|l|l|l|}
\hline & Marital Status & N & X & SS & P \\
\hline \multirow{2}{*}{$\begin{array}{l}\text { Attitude towards Addictive } \\
\text { Substances Scale }\end{array}$} & Together & 311 & 1.9872 & .76307 & \multirow{2}{*}{.865} \\
\cline { 2 - 6 } & Divorced & 15 & 1.9530 & .70042 & \\
\hline \multirow{2}{*}{ Beck Depression Inventory } & Together & 311 & 1.7676 & .66568 & \multirow{2}{*}{.102} \\
\cline { 2 - 6 } & Divorced & 15 & 2.0603 & .85704 & \\
\hline
\end{tabular}

According to the results of t-test which was applied in order to examine attitudes of high school students towards addictive substances in relation with their parents' marital status, no significant difference was determined. As a result, it can be stated that there isn't any correlation between parents' marital status and attitudes towards addictive substances and depression levels.

Table 8. T-test results according to income level variable

\begin{tabular}{|l|l|l|l|l|l|}
\hline & Income Level & N & X & SS & P \\
\hline \multirow{2}{*}{$\begin{array}{l}\text { Attitude towards Addictive } \\
\text { Substances Scale }\end{array}$} & $0-2000 \mathrm{TL}$ & 167 & 1.9099 & .74484 & \multirow{2}{*}{.065} \\
\cline { 2 - 6 } & $2001 \mathrm{TL}$ and over & 159 & 2.0650 & .76859 & \\
\hline \multirow{2}{*}{ Beck Depression Inventory } & $0-2000 \mathrm{TL}$ & 167 & 1.7790 & .62382 & \multirow{2}{*}{.956} \\
\cline { 2 - 6 } & $2001 \mathrm{TL}$ and over & 159 & 1.7832 & .73035 & \\
\hline
\end{tabular}

Note. ${ }^{*} \mathrm{P}<.05$.

T-test was done in order to determine if the average scores of Beck Depression Inventory and Attitude towards Addictive Substances Scale of the high school students show a significant difference in terms of income level variable. When the results are considered, the attitudes towards addictive substances and depression symptoms do not show a significant difference in terms of income level variable. 
Table 9. One-way Anova test results according to number of siblings variable

\begin{tabular}{|c|c|c|c|c|c|}
\hline & Number of Siblings & $\mathbf{N}$ & $\mathbf{x}$ & SS & $\mathbf{P}$ \\
\hline \multirow{6}{*}{$\begin{array}{l}\text { Attitude towards Addictive } \\
\text { Substances Scale }\end{array}$} & Only Child & 18 & 2.1515 & .74730 & \multirow{6}{*}{.653} \\
\hline & 1 sibling & 69 & 1.9991 & .79804 & \\
\hline & 2 siblings & 90 & 1.9035 & .70821 & \\
\hline & 3 siblings & 86 & 1.9754 & .78283 & \\
\hline & more than 3 siblings & 63 & 2.0545 & .76663 & \\
\hline & Total & 326 & 1.9856 & .75933 & \\
\hline \multirow{6}{*}{ Beck Depression Inventory } & Only Child & 18 & 1.7275 & .55118 & \multirow{6}{*}{.416} \\
\hline & 1 sibling & 69 & 1.7964 & .66716 & \\
\hline & 2 siblings & 90 & 1.7884 & .68870 & \\
\hline & 3 siblings & 86 & 1.6838 & .61279 & \\
\hline & more than 3 siblings & 63 & 1.9017 & .77786 & \\
\hline & Total & 326 & 1.7810 & .67683 & \\
\hline
\end{tabular}

As a result of One-Way Anova analysis which was applied in order to determine if there is a correlation among the average scores obtained from Beck Depression Inventory by the high school students and the number of siblings variable, it was determined that the difference among them is not significant. One-Way Anova was applied in order to determine the correlation between the average scores obtained from Attitude towards Addictive Substances and the number of siblings variable and a significant difference could not be determined.

\section{Discussion}

This study has been made in order to analyze the correlation between depression and attitude towards addictive substances in high school students who participate in regular exercise and the students who do not participate in regular exercise. To that end, sociodemographic information form was used in order to measure the sociodemographic features of the participants. The averages were found as appropriate level to carry on with the measurement. At the same time, 326 individuals studying at high school answered Beck Depression Inventory and Attitude towards Addictive Substances Scale in order to measure the main subject.

According to the findings, the attitude which shows interest towards addictive substances of the students who do sports in adolescent years is higher than their peers who do not do regular sports. Thus, the individuals who do sports have a tendency to substance addiction more. The obtained results contradict the literature. No correlation has been determined between depression and sports participation. When the studies carried out in the literature is considered, this situation also contradicts the expectations. 
In the study carried out in Germany, 1000 high school students were taken in the study and it was found that the students doing sports have a higher self-concept, and they are less likely to use substances when compared to the students not doing sports; also they have less anxiety, depression or psychological problems (Kim, 2003). Baştürk (2000) found in his study that the substance use in high schools were high and mentioned that informing the students about the matter was very important. Also Doğan (2006) studied correlation between sports and depression. According to his study, doing sports increases noradrenalin and dopamine release. Therefore these result in a positive mood.

On the other hand, 170 female and 156 male students took part in the study for the evaluation according the sex variable. As a result of the analysis, it was seen that the tendency towards addictive substances in male students is greater than the female students. Also whereas the students studying at vocational and technical high schools have higher tendencies towards using addictive substances, their depression symptom scores are also higher although they are not as high as addictive substance use scores. When considered in terms of class years, in other words their grades, of the students, it was seen that $12^{\text {th }}$ grade students' both depression symptom scores and their tendency towards abusive substances use is higher. At the same time, as the grade increase, the complexity of adolescence period increases and also the stress caused by university entry exams is added up. According to these results, it can be stated that the tendency for addictive substances and depression level in Vocational and Technical High School students is higher than Anatolian High School students. There are different studies carried out about this subject. In the studies of Yelkenci (2013), and Aydin (1989), it was found that female students show more depression symptoms than the male students. In the studies of Düzgün (1995), and Ören and Gençdoğan (2007), no correlation between depression and sex were found. Aslan et. al. stated that male students have a higher tendency of smoking, consuming alcohol and using addictive drugs and also as the grades increase, the rate of these also increases. Erdamar and Kurupinar (2014) obtained similar results in their study. They found that male students tend to drink alcohol and smoke. Also, according to Erdamar and Kurupinar, $12^{\text {th }}$ grade student and vocational high school students have a higher tendency for addiction when compared to other students. Yildiz (2009) states that male students and upper grade students have more cigarette, alcohol and drug addictions.

In this study, no correlation between family income level and attitude towards addictive substances and depression symptoms was found. However, Toker (2008) argued that income level has an effect on use of substances. Similarly, Gökler and Koçak (2008) argued that factors such as sex, economic situation and age have effects on depression symptoms. Karatay (2004) studied on public and foundation schools. While no differences were found among these schools, foundation schools got a higher score in terms of use of substances. According to Çavuşoğlu (2009), substance use in students differs in terms of age, grade and education level of the mother. When considered in terms of number of siblings, a difference was determined only in the students who have more than three siblings in terms of depression symptoms. Zeren et al. (2012) couldn't determine a correlation between number of siblings and depression symptoms. Nevertheless, they pointed out the high level of depression in individuals with low income levels. Kourt (2011) stated that as the number of siblings 
increase, the level of depression increases. Mutallimova (2013) states that the number of siblings does not have an effect on depression.

It is observed in this study that divorced parents have an effect on depression symptoms. It can be stated that the students with divorced parents have a higher level of depression. Whereas this situation can be classified as expected, it can be said that there is a collapse caused by a traumatic process for the children. The children of the divorced parents carry the emotion of loneliness and withdrawal from society as well as the emotion of loss. Mutallimova (2013) and Sönmez (2015) thought that the situation of divorce affect the depression symptoms.

In the light of obtained results, in this study in which the students doing sports can be said to have a higher tendency for addictive substances; it was found that the students who do regular exercise for more than five years have a higher rate of depression symptoms. Attitude towards addictive substances score and depression symptoms scores of the individuals who do sports everyday were found higher. In contrast to the literature, it can be said that the individuals who do sports for a long time and who do it regularly have a higher symptoms for depression and addiction. Although it is rather hard to find negative effects of the sports, Arslan et al. (2012) stated in their study on the students who do sports and who do not do sports that the students participating in regular exercise have a higher level of depression; and that the depression symptoms do not vary according to the sports branches.

As a consequence, while the obtained results of this study can be evaluated in these frames, the tendency of depression and substance addiction in the period of adolescence which is really complex cannot be regulated via solely sports. Both cultural structure and sociodemographic variables have effects on this situation. This study will shed a light for the researchers who carry out studies on attitude towards addiction and adolescence depression with the point of view of sports. At the same time, the educators working with adolescents and parents living with adolescents will benefit thanks to this study; and it will show that there are many cultural, sociological, psychological, economic, physiological and biological factors to be changed and improved except for sports.

\section{Acknowledgements}

The authors thank Gürkan Kavak who participated in this study.

\section{References}

Aksoy, K. (2006). The analysis of attitudes of high school students towards addictive substances and variables affecting these attitudes (sample of the province of Malatya) (Unpublished postgraduate thesis, İnönü University, Malatya).

Alisinanoğlu, F. (2002). Features of youth period and communication between the youth and their parents. Education and Science, 27(123), 62-63.

Alpaslan, A. H. (2012). Adolescent Psychological Health and Sports. Kocatepe Medical Journal, 13, 181-185. 
Arslan, C., Güllü, M., \& Tutal, V. (2011). Analysis of depression situation of secondary school students who do and who do not do sports according to certain variables. Niğge University Physical Education and Sports Sciences Journal, 5(2), 120-132.

Aydin, B. (1989). The analysis of study habits and attitudes of a fragment of students and their depression levels. Education Sciences Journal, 1, 8-15.

Babuna, C., \& Bayhan, N. (2009). Drugs-addiction disaster and problems. İstanbul: Kara Kutu Publications.

Baştürk, P. (2000). The analysis of informing high school students and its effect on their perception of substances (Postgraduate thesis, Institute of Forensics, İstanbul University, İstanbul).

Cengil, M. (2003). The role of religious beliefs in preventing depression. Religious Sciences Academic Researh Journal, 2, 129-151.

Çavuşoğlu, F. (2009). The factor affecting use of substances of school of health service and the effect of social support from family (Postgraduate thesis, Public Health Nursing Department, Ondokuz Mayıs University, Samsun).

Doğan, T. (2006). The analysis of wellbeing of university students. The Journal of Education Faculty, 30(30).

Düzgün, Ş. (1995). Correlations between psychological symptoms of high school students and parents attitudes (Unpublished doctoral dissertation, Institute of Social Sciences, Erzurum).

Erdamar, G., \& Kurupınar, A. (2014). The habit and extensity of substance addiction found in secondary education. Journal of Social Sciences, 16(1), 65-84.

Gül, S. K., \& Güneş, İ. D. (2009). Adolescence period problems and violence. Journal of Social Sciences, 11, 79-101.

Güney, M. (1998). The depressions of adolescent period. Psychiatry World, 2, 41-44.

Hisli, N. (1988). A study on the validity of Beck depression inventory. Journal of Psychology, $22,118-126$.

İçli, T. (1999). Criminology (3rd ed.). Ankara: Semih Ofset Press.

Karamustafalığlu, O., \& Yumrukçal, H. (2011). Depression and anxiety disorders. Medical Bulletin of Şişli Etfal Hospital, 45(2).

Karatay, G., \& Kubilay, G. (2004). Use of substance in two different high schools with different socioeconomic levels and determining the affecting factors. Journal of Research and Development in Nursing, S1(2).

Kim, Yh. (2003). Correlation of Mental Health Problems with Psychological Constructs in Adolescence: Final Results from A 2-Year Study. Int J Nurs Stud, 40, 115-24. 


\section{Macrothink}

Kourt, R. (2011). The Investigation of the Relationship of Childhood Trauma with Dissociative Experiences and Guilt-Embarrassing Emotions in University Students between the ages of 18-24 (Postgraduate thesis, Department of Psychology, Institute of Social Sciences, Maltepe University, İstanbul).

Mutallimova, S. (2014). The Relationship Between Depression Level and Parental Attitude in High School Students (Postgraduate thesis, Institute of Social Sciences, Arel University, İstanbul).

Ören, N., \& Gençdoğan, B. (2007). Evaluation of Depression Levels of High School Students According to Some Variables. Kastomonu Education Journal, 15, 85-92.

Öztürk, F., \& Şahin, Ş. K. (2007). Comparison of Social Self-Efficacy Expectation Points of 9-13 Year-Old Individuals Who Do Sports and Do Not (Bursa Case). Illkögretim Online, 6(3), 469-479.

Salar, B., Hekim, M., \& Tokgöz, M. (2012). Comparing the Emotional Situations of 15-18 Age Group Doing Team and Individual Sports. Journal of Social Sciences Institute, 6, 123-135.

Sönmez, S. (2015). Investigation of Depression Levels and Satisfaction with Life of Adult Individuals with Mental Trauma in Childhood (Postgraduate thesis, Psychology Department, Institute of Social Sciences, Beykent University, İstanbul).

Toker, T. (2008). The Relationship between Childhood Aggression Experiences, Substance Use, Self Esteem and Coping Attitudes (Postgraduate thesis, Karadeniz Technical University, Trabzon).

Türker, K. (2016). Investigation of Psychosocial Factors Causing Substance Use in Adolescents (Postgraduate thesis, Gaziosmanpaşa University, Tokat).

Yelkenci, İ. (2013). Investigation of Depression and Anxiety Levels of Students Prepared for University Examination by Various Variables (Postgraduate thesis, İstanbul Arel University Institute of Social Sciences Department of Psychology, İstanbul).

Y1ldı, E. (2009). Smoking, Alcohol, Drug Use Prevalence, Prepatory and Protective Factors in Izmir High Schools (Doctoral dissertation, Institute of Social Sciences, Ege University, İzmir).

Zeren, C., Yengil, E., Celikel, A., Arık, A., \& Arslan, M. (2012). Prevalence of Childhood Abuse in University Students. Dicle Medical Journal, 39(4), 536-541. 


\section{Copyright Disclaimer}

Copyright for this article is retained by the author(s), with first publication rights granted to the journal.

This is an open-access article distributed under the terms and conditions of the Creative Commons Attribution license (http://creativecommons.org/licenses/by/3.0/). 